\title{
Cortical Thinning Associated with Mild Cognitive Impairment in Parkinson's Disease.
}

B. Segura (PhD) 2, 3, H. C. Baggio (MD) 2, 3, M. J. Marti (MD, PhD)1,2,4, F. Valldeoriola (MD, PhD)1,2,4, Y. Compta (MD, PhD)1,2,4,, A.I. Garcia-Diaz (PhD)3, P. Vendrell (PhD)1,2,3, N. Bargallo (MD, PhD) 5, E. Tolosa (MD, PhD)1,2,4, C. Junque (PhD)1,2,3

1 Centro de Investigación en Red de Enfermedades Neurodegenerativas (CIBERNED), Hospital Clínic de Barcelona, Catalonia, Spain.

2 Institute of Biomedical Research August Pi i Sunyer (IDIBAPS), Catalonia, Spain.

3 Department of Psychiatry and Clinical Psychobiology, University of Barcelona, Catalonia, Spain.

4 Parkinson's Disease and Movement Disorders Unit, Neurology Service, Institut Clínic de Neurociències (ICN), Hospital Clínic de Barcelona, Catalonia, Spain.

5 Centre de Diagnostic per la Imatge, Hospital Clinic, Barcelona, Spain

Corresponding author: Carme Junque (PhD)

Department of Psychiatry and Clinical Psychobiology. University of Barcelona

Casanova 143 (08036) Barcelona, Spain

Phone: (+34) 934024570 // Fax: (+34) 934035294 // E-mail: cjunque@ub.edu

Running title: Cortical thinning and cognition in PD

Key words: Parkinson disease, cortical thickness, cognition.

\section{Disclosure:}

This work was funded by the Spanish Ministry of Science and Innovation [PSI2010-16174 grant to C.J., H.C.B. and B.S.], and by Generalitat de Catalunya [2009 SGR0836 to E.T., 2009SGR0941 to C.J.] and an FI-DGR grant [2011FI_B 00045] to H.C.B., and CIBERNED.

The authors report no conflicts of interest.

Word count

Abstract: 241

Manuscript text: 3371 


\section{Abstract}

Objective: The aim of this study was to investigate patterns of cortical atrophy associated with mild cognitive impairment in a large sample of non-demented PD patients, and its relation with specific neuropsychological deficits.

Methods: MRI and neuropsychological assessment were performed in a sample of 90 nondemented PD patients and 32 healthy controls. All underwent a neuropsychological battery including tests that assess different cognitive domains: attention and working memory, executive functions, memory, language and visuoperceptual-visuospatial functions. Patients were classified according to their cognitive status as PD patients without mild cognitive impairment $(n=43)$ and PD patients with mild cognitive impairment $(n=47)$. Freesurfer software was used to obtain maps of cortical thickness for group comparisons and correlation with neuropsychological performance.

Results: Patients with mild cognitive impairment showed regional cortical thinning in parietotemporal regions, increased global atrophy (global cortical thinning, total gray matter volume reduction and ventricular enlargement), as well as significant cognitive impairment in memory, executive and visuospatial and visuoperceptual domains. Correlation analyses showed that all neuropsychological tests were associated with cortical thinning in parieto-temporal regions and to a lesser extent in frontal regions.

Conclusion: These results provide neuroanatomic support to the concept of $\mathrm{MCl}$ classified according to Movement Disorders Society criteria. The posterior pattern of atrophy in temporoparietal regions could be a structural neuroimaging marker of cognitive impairment in nondemented PD patients. All the neuropsychological tests reflected regional brain atrophy but there were no specific patterns corresponding to impairment in distinct cognitive domains. 


\section{INTRODUCTION}

Parkinson's disease is associated with cognitive decline [Aarsland et al., 2009; Elgh et al., 2009; Foltynie et al., 2004; Muslimovic et al., 2005] that may predict dementia at later stages [Aarsland et al., 2009; Janvin et al., 2006; Pedersen et al., 2013].Between 18.9 and 38.2\% of patients meet mild cognitive impairment $(\mathrm{MCl})$ criteria [Litvan et al., 2011a]. Indeed, the proportion of patients fulfilling $\mathrm{MCl}$ criteria increased from one-third to approximately $50 \%$ of patients without dementia after five years from diagnosis [Broeders et al., 2013]. There is a great variability in the description and proportion of subtypes of $\mathrm{MCl}$ in PD [Aarsland et al., 2009; Caviness et al., 2007; Janvin et al., 2006], due perhaps to the number and type of tests used and the classification of the tests by domains.

The recognition of $\mathrm{PD}$ patients with $\mathrm{MCl}(\mathrm{PD} \mathrm{MCl})$ has led to studies searching for biological markers associated with this diagnosis. Several MRI studies have investigated the relationship between brain atrophy and specific cognitive deficits in non-demented PD, such as deficits in memory [Brück et al., 2004; Camicioli et al., 2003; Ibarretxe-Bilbao et al., 2008; Junqué et al., 2005; Litvan et al., 2012; Pereira et al., 2013; Riekkinen et al., 1998; Tam et al., 2005], verbal fluency [Pereira et al., 2009a], visuospatial and visuoperceptual ability [Pereira et al., 2009b] and decision-making and emotional processing [lbarretxe-Bilbao et al., 2009]. Recently, Filoteo et al., using region-of-interest analyses, associated subtle changes in multiple cognitive domains with distinct patterns of regionally-specific volume changes in non-demented PD patients [Filoteo et al., 2014]. However, to the best of our knowledge, no published MRI studies have focused on whole brain neuroanatomical correlates of the different tests included in cognitive domains assessed by an extensive neuropsychological battery.

Few studies have investigated the neuroanatomical correlates of $\mathrm{MCl}$. Initially, voxel based morphometry (VBM) analyses showed that PD-MCl had reduced cortical gray matter (GM) density in the left middle frontal gyrus, precentral gyrus, left superior temporal lobe and right inferior temporal lobe in comparison with cognitively intact PD patients [Beyer et al., 2007]. In contrast, Song et al. reported gray matter density decreases in frontal regions of PD-MCl patients in comparison to PD without $\mathrm{MCl}$ (PD non-MCI) [Song et al., 2011]. Recently, VBM analyses with a large sample of 148 PD patients did not reveal any areas of significant GM loss in participants with PD-MCl compared with controls [Yarnall et al., 2014]. 
In order to clarify these controversial results, certain methodological issues need to be addressed. VBM and volumetric analyses may be insufficient to detect early cortical changes in PD MCI patients. Recent studies using cortical thickness measures suggest that this method may be more sensitive than VBM to identify regional GM changes associated with PD [Pereira et al., 2012]. Cortical changes associated specifically with $\mathrm{MCl}$ in $\mathrm{PD}$ have not been investigated in depth. In a small sample, Biundo et al. showed significant regional thinning in right parietal-frontal areas and in left temporal-occipital areas in $\mathrm{PD} \mathrm{MCl}$ in comparison with $\mathrm{PD}$ non- $\mathrm{MCl}$ [Biundo et al., 2013]. Studying a bigger sample, Pagonabarraga et al., using an uncorrected level of significance showed both increases and decreases in cortical thickness of PD MCl patients in comparison to PD non- $\mathrm{MCl}$ [Pagonabarraga et al., 2013], and Hanganu et al. did not find significant cortical thinning in PD MCl subjects compared with PD non-MCl, but detected a small cluster with increased thickness in the left middle temporal gyrus [Hanganu et al., 2013]. Recently, Pereira et al. studied a large multicentric cohort of drug-naïve PD patients with early $\mathrm{PD}$, the authors found mainly temporal and parietal cortical thinning in the PD $\mathrm{MCl}$ group compared to PD non- $\mathrm{MCl}$ patients, using a cognitive-domain approach [Pereira et al., 2014].

In light of these previous results, the aims of this study were (1) to investigate whether different anatomical patterns of cortical atrophy distinguish PD patients with mild cognitive impairment from patients without cognitive impairment in a large sample of non-demented PD patients, and (2) whether different anatomical patterns of cortical atrophy are associated with neuropsychological deficits commonly related to specific cognitive domains. This is of crucial importance for validating $\mathrm{MCl}$ criteria, and may help to clarify the neural correlates of cognitive impairment in PD.

\section{Methods}

\section{Subjects}

The study included 121 consecutive PD patients recruited from an outpatient movement disorders clinic (Parkinson's Disease and Movement Disorders Unit, Department of Neurology, Hospital Clinic, Barcelona, Spain) and 49 healthy subjects who volunteered to take part in studies addressing age-related processes at the Institut de l'Envelliment (Aging Institute). The 
inclusion criteria were: (i) fulfilling the UK PD Society Brain Bank (PDSBB) diagnostic criteria for PD [Daniel and Lees, 1993]; (ii) no surgical treatment with deep brain stimulation. The exclusion criteria were: (i) presence of dementia according to the Movement Disorders Society criteria (34), (ii) Hoehn and Yahr scale score $>3$ (iii) juvenile-onset PD, (iii) presence of psychiatric or neurological comorbidity, (iv) low global IQ estimated by the Vocabulary subtest of the Wechsler Adult Intelligence Scale, 3rd edition (scaled score $\leq 7$ points), (vi) Mini-mental state examination (MMSE) score <25, (vii) presence of claustrophobia, (viii) pathological magnetic resonance imaging (MRI) findings other than mild white matter hyperintensities in long-TR sequences, and (ix) MRI artifacts.

Ninety PD patients and 32 healthy volunteers were finally selected. Twelve patients and eight controls were excluded because they fulfilled criteria for dementia or other neurological disease, six PD patients for psychiatric comorbidity, one PD patient who scored higher than 3 on the H\&Y scale, one PD patient who presented young-onset PD, three PD patients and one control who presented low global IQ scores, two PD patients for claustrophobia, three healthy subjects who did not complete the neuropsychological assessment, and two controls and two PD patients due to MRI artefacts. We also excluded four patients and three controls aged below 50 years.

Motor symptoms were assessed by means of the UPDRS-III, motor section. All PD patients were taking antiparkinsonian drugs, consisting of different combinations of L-DOPA, COMT inhibitors, MAO inhibitors, dopamine agonists and amantadine.

This study was approved by the ethics committee of the University of Barcelona. Written informed consent was obtained from all study subjects after full explanation of the procedures involved.

\section{Neuropsychological assessment}

We selected a neuropsychological battery to assess cognitive functions usually impaired in PD [Aarsland et al., 2009; Muslimovic et al., 2005]. This battery is recommended by the Movement Disorder Society task force to evaluate cognitive functions in PD [Daniel and Lees, 1993; Litvan et al., 2011b], and is able to detect mild cognitive impairment in PD (Level I or Level II criteria 
for PD-MCl, bar language, for which a single measure was used [Litvan et al., 2012]. Attention and working memory were assessed with the Trail Making Test (TMT) (in seconds), part A (TMT-A) and part B (TMT-B), Digit Span Forward and Backward and the Stroop Color-word Test and Symbol Digits Modalities Tests (SDMT); executive functions were evaluated with Phonemic (words beginning with the letter "p" in one minute) and Semantic (animals in one minute) fluencies; language was assessed by the total number of correct responses in the short version of the Boston Naming Test (BNT), memory through total learning recall (sum of correct responses from trial I to trial $\mathrm{V}$ ) and delayed recall (total recall after 20min) through scores on Rey's Auditory Verbal Learning Test (RAVLT). Visuospatial and visuoperceptual functions were assessed with Benton's Judgement of Line Orientation (JLO) and Visual Form Discrimination (VFD) tests.

Initially, z scores for each test and for each subject were calculated based on the control group's means and standard deviations. Expected z scores adjusted for age, sex and education for each test and each subject were calculated based on a multiple regression analysis performed in the healthy control group [Aarsland et al., 2009].

We classified subjects as having $\mathrm{MCl}$ if the $\mathrm{z}$ score for a given test was at least 1.5 lower than the expected score in at least two tests in one domain, or in at least one test per domain in at least two domains. As expected [Muslimovic et al., 2005], most subjects with abnormalities had deficits in more than one function, precluding the creation of patient groups with single-domain impairments. Patients' cognitive complaints were recorded during the clinical interview.

Z composite scores were computed in order to obtain global cognitive measures (attention and working memory, executive, memory and visuospatial/ visuoperceptual functions).

\section{Neuropsychological and Clinical Statistical Analysis}

All statistical analyses were performed using SPSS Statistics 20, release version 20.0.0 (Armonk, NY, http://www-01.ibm.com/software/analytics/spss/). Statistical significance threshold was set at $p<0.05$. Pearson's chi-square test was used to compare categorical variables (sex and Hoehn and Yahr stage). Separate-variance test (Welch t) was used to test between-group differences $(\mathrm{HC}, \mathrm{PD} \mathrm{MCl}, \mathrm{PD}$ non- $\mathrm{MCl})$ in quantitative clinical and demographic variables. ANCOVAs including age and education as confounding variables were used to compare the 
performance on neuropsychological tests and composite scores for each domain. Bonferroni correction was used to control for the number of intergroup comparisons.

\section{Image acquisition}

Magnetic resonance images were acquired with a $3 T$ scanner (MAGNETOM Trio, Siemens, Germany). The scanning protocol included high-resolution 3-dimensional T1-weighted images acquired in the sagittal plane (TR=2300 ms, TE=2.98 ms, TI $900 \mathrm{~ms}, 240$ slices, FOV=256 mm; matrix size=256x256; $1 \mathrm{~mm}$ isotropic voxel) and axial FLAIR sequence (TR=9000 ms, TE=96 $\mathrm{ms})$.

\section{Cortical thickness}

Cortical thickness was estimated using the automated FreeSurfer stream (version 5.1; available at: http://surfer.nmr.harvard.edu). The procedures carried out by FreeSurfer software include removal of non-brain data, intensity normalization [Sled et al., 1998], tessellation of the gray matter/white matter boundary, automated topology correction [Fischl et al., 2001; Ségonne et al., 2007] and accurate surface deformation to identify tissue borders) [Dale et al., 1999; Dale and Sereno, 1993; Fischl and Dale, 2000]. Cortical thickness is then calculated as the distance between the white and gray matter surfaces at each vertex of the reconstructed cortical mantle [Fischl and Dale, 2000]. In our study, results for each subject were visually inspected to ensure accuracy of registration, skull stripping, segmentation, and cortical surface reconstruction. Maps were smoothed using a circularly symmetric Gaussian kernel across the surface with a full width at half maximum (FWHM) of $15 \mathrm{~mm}$.

Comparisons between groups were assessed using a vertex-by-vertex general linear model. The model included cortical thickness as a dependent factor and diagnosis (controls, PD non$\mathrm{MCl}, \mathrm{PD} \mathrm{MCl}$ ) as an independent factor, and also included age and education as nuisance variables (https://surfer.nmr.mgh.harvard.edu/fswiki/FsgdFormat). All results were corrected for multiple comparisons by using a pre-cached cluster-wise Monte-Carlo Simulation. Significance level was set at $p<0.05$.

In the PD patient group, the vertex-by-vertex general linear model was used to assess the relationship between cortical thickness and neuropsychological tests. Positive and negative associations between a specific neuropsychological test and cortical thickness were analyzed using Qdec. Initially, a simple model without covariates was tested for each neuropsychological 
measure. Complementarily, we performed a conservative analysis of covariance including age, education and gender as confounding variables. An initial vertex-wise threshold was set to $p=0.005$ to find clusters. In order to avoid clusters appearing significant purely by chance (i.e., false positives), Monte-Carlo simulation with 10,000 repeats was tested (absolute value). Results were reported at cluster-wise probability significance level set at $p<0.05$.

\section{Global atrophy measures}

Global average thickness for both hemispheres was calculated ((left hemisphere thickness*left hemisphere surfarea)+(right hemisphere thickness*right hemisphere surface area))/(left hemisphere surface area+right hemisphere surface area)).

Total GM volume and total subcortical volumes, as well as mean lateral ventricular volume and estimated Total Intracranial Volume (eTIV) were obtained automatically via whole brain segmentation [Fischl et al., 2002]. An ANCOVA including eTIV, age and education was used to compare subcortical volumes between groups. Significant $p$ values were adjusted using posthoc Bonferroni tests considering the number of intergroup comparisons.

\section{Results}

Forty-seven patients (52.2\%) fulfilled the criteria for $\mathrm{MCl}$. Table 1 shows sociodemographic and clinical data and the corresponding group comparisons.

Insert Table 1

\section{Neuropsychological differences between groups.}

Table 2 shows differences in neuropsychological performance between groups. $\mathrm{MCl}$ patient scores were significantly worse than those of non- $\mathrm{MCl}$ patients and healthy controls in all tests except Forward and Backward Digits. Forty-two patients (46.6\%) showed impairments in attention and working memory, $31(34.4 \%)$ in memory, $26(28.8 \%)$ in executive and also visuoperceptual and visuospatial domains, and only four (4.4\%) in language.

Insert Table 2

\section{Global atrophy comparison between groups}

There were significant differences in global atrophy between healthy controls and PD patients groups according to $\mathrm{MCl}$ status. PD $\mathrm{MCl}$ patients showed decreased total mean thickness and 
total GM volume, as well as increased mean lateral ventricle volume in comparison to healthy controls and PD non-MCI. There were no significant differences in total subcortical volume (Table 3). Finally, there were no significant results after the inclusion of disease duration as a nuisance variable in the covaried model.

\section{Insert Table 3}

\section{Cortical thickness comparison between groups}

Surface-based cortical thickness analyses showed a group effect according to cognitive status (Figure 1). $\mathrm{PD} \mathrm{MCl}(\mathrm{PD} \mathrm{MCl}<\mathrm{HC}$ ) showed cortical thinning in widespread bilateral regions, including parietal (superior and inferior, supramarginal and also precuneus regions), temporal (posterior middle temporal, inferior temporal, fusiform and parahippocampal regions) and occipital cortices (bilateral posterior occipital), but also in left frontal superior and rostral middle areas. There were significant differences between controls and PD non- $\mathrm{MCl}$ (PD non- $\mathrm{MCl}<$ $\mathrm{HC}$ ) specifically in bilateral superior parietal regions. $\mathrm{PD} \mathrm{MCl}(\mathrm{PD} \mathrm{MCl}<\mathrm{PD}$ non-MCl) showed significant thinning in right precuneus and supramarginal regions compared to PD non-MCI. There were no significant results after including disease duration as a nuisance factor in the covaried model.

Insert Figure 1 and supplementary material Table 1

\section{Correlations between neuropsychological tests and cortical thickness in PD patients}

Vertex-wise regression analyses showed correlations between regional cortical thickness and neuropsychological test performance (Supplementary Material). We found a common posterior atrophy pattern for all the neuropsychological tests evaluated, and there were no specific patterns of atrophy related to neuropsychological domains.

Stroop Test (Words, Colours and Word-Colours), TMT A, Semantic fluency and RAVLT total learning performance correlated with gray matter thinning in bilateral medial and lateral areas. Performance on VFD, JLO and TMT B was associated only with medial temporal-parietal atrophy. Atrophy in anterior regions, mostly left superior frontal gyrus, also correlated with Stroop Test, TMTA, SDMT, phonemic fluency and RAVLT total learning. In addition, negative correlations with SDMT and JLO were also found in rostral middle frontal gyrus (Supplementary Figure 1 and material table 2). After controlling for the effect of age, education, and gender, only Stroop Words Test and Semantic fluency showed a significant positive correlation with cortical 
thickness. Stroop Words Test correlated with left medial orbitofrontal, right superior temporal and right insula. Semantic fluency correlated with right precuneus and lingual gyrus thickness. (Figure 2. and supplementary material 3). There were no significant results after including disease duration as a nuisance factor in the covaried model.

Insert Figures 2

\section{Discussion}

Patients with $\mathrm{MCl}$ showed a posterior pattern of atrophy, characterized by cortical thinning in the bilateral superior parietal and supramarginal regions and in the inferior temporal area, parahippocampal gyrus, fusiform gyrus and precuneus. Cortical thinning was also observed in the left rostral frontal region. Moreover, $\mathrm{PD} \mathrm{MCl}$ and $\mathrm{PD}$ non- $\mathrm{MCl}$ patients differed in right lateral parietal regions and precuneus.

Our results of cortical thickness reductions in the parietal, temporal and frontal regions could be related to previous PET data [Garcia-Garcia et al., 2012] showing that PD-MCl patients exhibited reduced FDG uptake in the parietal and occipital lobes and in localized areas of the frontal and temporal lobes compared with controls. In addition, longitudinal neuropsychological studies suggest that the dementia process is heralded by posterior-cortically-based cognitive deficits [Williams-Gray et al., 2007; Williams-Gray et al., 2009]. In sum, parieto-occipital changes seem to correspond to the deterioration that may eventually lead to dementia, possibly reflecting gradual loss of synaptic terminals, dendritic arborisation and size of neuronal cell bodies.

In our study, PD groups differed by degree of atrophy in right lateral parietal regions and the precuneus. This finding, together with the right asymmetry of atrophy detected in the PD non$\mathrm{MCl}$ group compared to controls, suggested an asymmetric pattern of deterioration, initially involving parietal and temporal regions, and progressively widespread to bilateral atrophy. Asymmetric atrophy has been found in previous studies when PD patients were compared to controls [Pereira et al., 2012].

Recently, PD MCl patients have been studied using cortical thickness measures. However, no consensus has been reached in relation to cortical thickness differences between PD $\mathrm{MCl}$ and 
PD non- $\mathrm{MCl}$; both increases and decreases have been reported in $\mathrm{PD} \mathrm{MCl}$, probably due to small sample sizes [Biundo et al., 2013; Hanganu et al., 2013; Pagonabarraga et al., 2013]. As expected, we observed thinning in PD $\mathrm{MCl}$ involving the sumpramarginal gyrus and the precuneus.

In addition to differences in regional cortical thickness, PD $\mathrm{MCl}$ patients had a reduction of global GM volume together with increased ventricular volume in comparison to PD non- $\mathrm{MCl}$ and healthy controls. These results, similar to those of previous studies [Apostolova et al., 2012; Dalaker et al., 2010; Weintraub et al., 2011], confirm that cognitive deficits seen in PD MCl are related to structural brain changes, probably in combination with neurochemical changes.

The current study also aimed to establish whether specific neuropsychological tests used in clinical practice reflect the degree of regional atrophy in PD patients. Cognitive domains are defined under the assumption that they represent specific functions mediated by specific brain regions. The 'anterior' (frontal) pattern is putatively associated with executive functions, the 'posterior' (temporo-parietal) pattern with visuospatial and visuoperceptual functions, and hippocampal degeneration with the amnestic pattern [Lezak, 2004]. Grouping different tests into a single function without knowing the specific correlates of each test may generate confusion. The study of neuroanatomical correlates of specific tests is the first step in the discussion of domains and in determining whether subtypes of mild cognitive impairment exist in PD, and consequently whether they are useful in predicting the evolution to dementia. In line with this statement, our results showed a common posterior atrophy pattern for all the neuropsychological tests evaluated. Only the Stroop Test, SDMT and phonemic fluency, classified by recent guidelines [Litvan et al., 2012] as measures of attention and executive function respectively, had an extended pattern including medial anterior regions. We did not observe any specific dorsolateral prefrontal or limbic pattern of correlations. Analysing the global patterns of correlations, a group of tests including Stroop Test (Words, Colors and WordColors), TMT-A, Semantic fluency and RAVLT total learning correlated with extensive gray matter loss involving bilateral medial and lateral cortical regions, whereas VFD, JLO and TMT-B only correlated with medial temporal-parietal regions. Analyses of covariance only showed a positive correlation between semantic fluency and temporal-parietal regions and a positive correlation between Stroop words and left medial orbitofrontal, right superior temporal and right 
insular regions. In sum, we did not find specific patterns of atrophy related to the neuropsychological domains, either with or without the use of covariates in the analyses.

Interestingly, semantic fluency performance remained significantly correlated with the precuneus after controlling for the effects of age, education, and gender. These results agree in part with current pathophysiological models that dissociate the substrates and prognostic values of different types of cognitive impairment in PD, and show that tests with posterior cortical bases (semantic fluency and ability to draw an interlocking pentagon) reflecting probable nondopaminergic cortical Lewy body or Alzheimer's type pathology were associated with dementia, whereas frontostriatal executive deficits were not [Williams-Gray et al., 2009]. Our results indicate that semantic fluency is an easily administered test that should be included in the neuropsychological assessment of PD patients.

The consecutive recruitment of PD patients from an outpatient movement disorders clinic involves certain differences in clinical and demographical variables between PD groups. In this regard, disease duration was longer in $\mathrm{PD}-\mathrm{MCl}$ than $\mathrm{PD}$ non- $\mathrm{MCl}$ patients. In our study, additional analyses including disease duration as nuisance variable in the co-varied models did not show significant results. A previous study has shown that neurodegeneration is likely to occur faster in PD patients with $\mathrm{MCl}$ [Hanganu et al., 2013]. Cortical degeneration was more advanced in patients who have PD MCl than in those without at the same stage of disease. In accordance with previous longitudinal studies [Williams-Gray et al., 2007; Williams-Gray et al., 2009], disease duration is correlates with PD patients' deterioration, including cognitive impairment and brain atrophy. In this sense, controlling for the effects of disease duration could represent an overcorrection, masking actual intergroup effects.

One possible limitation of our study is that, despite the inclusion of a variety of tests in the main cognitive domains defined in recent guidelines (attention and working memory, executive functions, memory and visuospatial and visuoperceptive functions) [Litvan et al., 2011b] we did not include the same number of tests in each cognitive domain, and language was assessed only with the BNT. This limitation may have raised the possibility of false negative cases in the PD non- $\mathrm{MCl}$ group, but would not have affected the classification of subjects currently included in PD MCl group. 
In sum, degeneration was characterized by a posterior pattern of atrophy mostly involving posterior parietal-temporal areas, which extended to frontal regions in the PD $\mathrm{MCl}$ group compared to healthy controls. All the neuroanatomical correlates associated with neuropsychological tests involve this posterior pattern of atrophy, semantic fluency being the neuropsychological test with the most significant association. Our findings therefore suggest the presence of posterior structural degenerative brain changes in $\mathrm{PD} \mathrm{MCl}$ patients, evidencing a structural neuroimaging marker of this pathological condition and its possible evolution to dementia.

Acknowledgment

Without the support of the patients, their families and control subjects this work would have not been possible.

\section{AUTHOR ROLES:}

1. Research project: A. Conception, B. Organization, C. Execution;

2. Statistical Analysis: A. Design, B. Execution, C. Review and Critique;

3. Manuscript: A. Writing of the first draft, B. Review and Critique

Segura: 1B, 1C, 2A, 2B, 3A; Baggio: 1B, 1C, 2B, 2C, 3B; Marti: 1B, 1C, 2C, 3B; Valldeoriola: 1B, 1C, 2C, 3B; Compta: 1B, 1C, 2C, 3B; Garcia-Diaz: 1C, 2B, 2C, 3B; Vendrell: 1B, 1C ,2C, 3B; Bargallo: 1B, 1C, 2C, 3B; Tolosa: 1B, 1C, 2C, 3B ; Junque: 1A, 1B, 1C, 2A, 2B, 2C, 3B;

Financial Disclosures of all authors (for the preceding 12 months).

Segura B. Grants: Spanish Ministry of Education and Science PSI2010-16174; Catalonia Government, 22009SGR94. Employment: Postdoctoral position University of Barcelona.

Baggio HC. Grants: Spanish Ministry of Education and Science PSI2010-16174; Catalonia Government, 22009SGR94. 
Marti MJ. Grants: Fundació la Marató de TV3 2006" (N-2006-TV060510), Instituto de Salud Carlos III (FISS). PI041600. Employment: Hospital Clínic i Provincial de Barcelona.

Valldeoriola F. Grants: FIS (Instituto de Salud Carlos III), Advisory boards: Boehringer, Ingelheim, Solvay. Employment: Hospital Clínic i Provincial de Barcelona.

Compta Y. Grants: FEP_Premios11 (Federación Española de Parkinson). PI041833. Employment: Hospital Clínic i Provincial de Barcelona, University of Barcelona

Garcia-Diaz Al. Spanish Ministry of Education and Science PSI2010-16174; Catalonia Government, 22009SGR94.

Vendrell P. Spanish Ministry of Education and Science PSI2010-16174; Catalonia Government, 22009SGR94. Employment: Full Professor University of Barcelona.

Tolosa E. Grants: European Project on Mendelian Forms of Parkinson's Disease (MEFOPA). CP-FP PI040438. Catalonia Government PI040510. Instituto de Salud Carlos III FISS CP06/00126. PI08015. Michael J. Fox Foundation for Parkinson Disease (MJFF) PI041639, PI042534, PI042549, PI042548. Spaniard Network for Research on Neurodegenerative Disorders: Center of Biomedic Investigation in Neurodegenerative Diseases (CIBERNED), PI2010/05. Employment: Hospital Clínic i Provincial de Barcelona, University of Barcelona

Junque C. Grants: Spanish Ministry of Education and Science (Spanish Ministry of Education and Science PSI2010-16174, Catalonia Government 22009SGR94, Intellectual Property Rights: Books Editorial: Masson, Sintesis, Glosa, Ariel, Ars Medica, Employment: Full Professor University of Barcelona. 
Table 1. Sociodemographic and clinical data from study groups.

\begin{tabular}{|c|c|c|c|c|}
\hline & $\begin{array}{c}\mathrm{HC} \\
\mathrm{n}=32\end{array}$ & $\begin{array}{c}\text { PD non-MCl } \\
n=43\end{array}$ & $\begin{array}{c}\mathrm{PD} \mathrm{MCl} \\
\mathrm{n}=47\end{array}$ & Test stats/p \\
\hline Age (yrs.) & $64.69 \pm 8.63$ & $60.77 \pm 10.51$ & $67.72 \pm 9.71$ & $5.243 / 0.007$ \\
\hline $\begin{array}{l}\text { Sex } \\
\text { (female/male) }\end{array}$ & $17 / 17$ & $29 / 21$ & $23 / 17$ & $0.61 \times / 0.738$ \\
\hline $\begin{array}{l}\text { Years of } \\
\text { education }\end{array}$ & $11.00 \pm 4.15$ & $12.02 \pm 5.05$ & $9.19 \pm 5.24$ & $3.47 / 0.036$ \\
\hline MMSE & $29.69 \pm 0.47$ & $29.47 \pm 0.74$ & $28.68 \pm 1.29$ & $11.998 /<0.001$ \\
\hline $\mathrm{BDI}$ & $6.00 \pm 5.65$ & $8.71 \pm 5.41$ & $12.63 \pm 6.41$ & $11.174 /<0.001$ \\
\hline $\begin{array}{l}\text { Disease } \\
\text { duration }\end{array}$ & & $6.23 \pm 4.05$ & $9.73 \pm 6.37$ & $9.845 / 0.002$ \\
\hline LEDD & & $\begin{array}{l}692.81 \\
\pm 452.801\end{array}$ & $\begin{array}{l}916.15 \\
\pm 507.944\end{array}$ & $4.863 / \mathbf{0 . 0 3 0}$ \\
\hline $\begin{array}{l}\mathrm{HY} \\
(1 / 1.5 / 2 / 2.5 / 3)\end{array}$ & & $14 / 5 / 19 / 3 / 2$ & $8 / 0 / 25 / 6 / 8$ & $11.900 \times / \mathbf{0 . 0 1 8}$ \\
\hline UPDRS-III & & $13.16 \pm 7.67$ & $17.79 \pm 11.07$ & $6.378 / \mathbf{0 . 0 2 3}$ \\
\hline
\end{tabular}

MMSE: mini-mental state examination. BDI: Beck's Depression Inventory-II scores. Disease duration: duration of motor symptoms, in years. LEDD: Levodopa equivalent daily dose, in mg. HY: Hoehn and Yahr scale. Pearson's chi-square (X). Age showed significant differences between PD MCl and PD non- $\mathrm{MCl}$ patients ( $p=.0003$, Bonferroni correction). MMSE showed significant differences between $\mathrm{PD} \mathrm{MCl}$ and both $\mathrm{PD}$ non- $\mathrm{MCl}$ and $\mathrm{HC}(\mathrm{p}<.001$, Bonferroni correction). BDI showed significant differences between PD MCI and both PD non- $\mathrm{MCl}(\mathrm{p}<.010$, Bonferroni correction) and $\mathrm{HC}(\mathrm{p}<.001$, Bonferroni correction). 
Table 2. Neuropsychological performance results for healthy controls and Parkinson's disease patients according to $\mathrm{MCl}$ status.

\begin{tabular}{|c|c|c|c|c|}
\hline & $\begin{array}{c}\mathrm{HC} \\
\mathrm{n}=32 \\
\text { mean (SD) }\end{array}$ & $\begin{array}{c}\text { PD non-MCI } \\
n=43 \\
\text { mean (SD) }\end{array}$ & $\begin{array}{c}\text { PD MCI } \\
n=47 \\
\text { mean (SD) }\end{array}$ & $F(p)$ \\
\hline \multicolumn{5}{|l|}{ Neuropsychological tests } \\
\hline VFD & $\begin{array}{l}29.44 \\
(2.75)\end{array}$ & $\begin{array}{l}29.47 \\
(2.22)\end{array}$ & $\begin{array}{l}26.17 \\
(3.81)\end{array}$ & $\begin{array}{l}11.171 \\
(<0.001)\end{array}$ \\
\hline $\mathrm{JLO}$ & $\begin{array}{l}23.88 \\
(3.46)\end{array}$ & $\begin{array}{l}23.42 \\
(3.93)\end{array}$ & $\begin{array}{l}19.67 \\
(4.99)\end{array}$ & $\begin{array}{l}7.90 \\
(0.001)\end{array}$ \\
\hline RAVLT total & $\begin{array}{l}44.75 \\
(6.27) \\
\end{array}$ & $\begin{array}{l}46.19 \\
(8.23) \\
\end{array}$ & $\begin{array}{l}32.81 \\
(7.47) \\
\end{array}$ & $\begin{array}{l}33.05 \\
(<0.001) \\
\end{array}$ \\
\hline RAVLT retrieval & $\begin{array}{l}9.13 \\
(2.12)\end{array}$ & $\begin{array}{l}9.26 \\
(2.60)\end{array}$ & $\begin{array}{l}6.00 \\
(2.30)\end{array}$ & $\begin{array}{l}18.92 \\
(<0.001)\end{array}$ \\
\hline SDMT & $\begin{array}{l}48.41 \\
(9.59)\end{array}$ & $\begin{array}{l}46.68 \\
(10.59)\end{array}$ & $\begin{array}{l}31.45 \\
(15.13)\end{array}$ & $\begin{array}{l}23.76 \\
(<0.001)\end{array}$ \\
\hline Digits Forwards & $\begin{array}{l}5.87 \\
(1.43)\end{array}$ & $\begin{array}{l}6.12 \\
(1.22)\end{array}$ & $\begin{array}{l}5.21 \\
(1.30)\end{array}$ & $\begin{array}{l}2.429 \\
(0.093)\end{array}$ \\
\hline Digits Backwards & $\begin{array}{l}4.19 \\
(1.28)\end{array}$ & $\begin{array}{l}4.51 \\
(0.99)\end{array}$ & $\begin{array}{l}3.83 \\
(0.89)\end{array}$ & $\begin{array}{l}1.982 \\
(0.142)\end{array}$ \\
\hline Stroop Words & $\begin{array}{l}100.16 \\
(14.31)\end{array}$ & $\begin{array}{l}98.90 \\
(21.28)\end{array}$ & $\begin{array}{l}72.68 \\
(17.12)\end{array}$ & $\begin{array}{l}24.465 \\
(<0.001)\end{array}$ \\
\hline Stroop Colours & $\begin{array}{l}62.47 \\
(15.32)\end{array}$ & $\begin{array}{l}66.31 \\
(12.39)\end{array}$ & $\begin{array}{l}47.30 \\
(11.91)\end{array}$ & $\begin{array}{l}18.50 \\
(<0.001)\end{array}$ \\
\hline Stroop Words-Colours & $\begin{array}{l}35.81 \\
(11.91)\end{array}$ & $\begin{array}{l}38.81 \\
(11.06)\end{array}$ & $\begin{array}{l}26.30 \\
(10.72)\end{array}$ & $\begin{array}{l}8.66 \\
(<0.001)\end{array}$ \\
\hline TMT A & $\begin{array}{l}38.94 \\
(14.90)\end{array}$ & $\begin{array}{l}37.09 \\
(15.69)\end{array}$ & $\begin{array}{l}80.83 \\
(61.78) \\
\end{array}$ & $\begin{array}{l}10.283 \\
(<0.001)\end{array}$ \\
\hline TMT B & $\begin{array}{l}90.41 \\
(31.54)\end{array}$ & $\begin{array}{l}90.21 \\
(35.94)\end{array}$ & $\begin{array}{l}187.78 \\
(122.34)\end{array}$ & $\begin{array}{l}21.40 \\
(<0.001)\end{array}$ \\
\hline Phonemic fluency & $\begin{array}{l}16.71 \\
(5.15)\end{array}$ & $\begin{array}{l}18.02 \\
(4.92)\end{array}$ & $\begin{array}{l}12.02 \\
(5.11)\end{array}$ & $\begin{array}{l}11.05 \\
(<0.001)\end{array}$ \\
\hline Semantic fluency & $\begin{array}{l}21.61 \\
(5.94)\end{array}$ & $\begin{array}{l}20.65 \\
(5.259)\end{array}$ & $\begin{array}{l}15.32 \\
(7.390)\end{array}$ & $\begin{array}{l}7.42 \\
(<0.001)\end{array}$ \\
\hline BNT & $\begin{array}{l}13.66 \\
(1.07)\end{array}$ & $\begin{array}{l}13.67 \\
(1.02)\end{array}$ & $\begin{array}{l}12.83 \\
(1.28)\end{array}$ & $\begin{array}{l}3.119 \\
(0.05) \\
\end{array}$ \\
\hline \multicolumn{5}{|l|}{ Z composite score } \\
\hline Attention/Working memory & $\begin{array}{l}0.07 \\
(0.47)\end{array}$ & $\begin{array}{l}0.09 \\
(0.39)\end{array}$ & $\begin{array}{l}-0.07 \\
(0.47)\end{array}$ & $0.974(0.381)$ \\
\hline Executive & $\begin{array}{l}0.06 \\
(0.88)\end{array}$ & $\begin{array}{l}0.14 \\
(0.86)\end{array}$ & $\begin{array}{l}-0.97 \\
(0.97)\end{array}$ & $\begin{array}{l}12.821 \\
(<0.0001)\end{array}$ \\
\hline Memory & $\begin{array}{l}0.05 \\
(0.93)\end{array}$ & $\begin{array}{l}0.19 \\
(1.24)\end{array}$ & $\begin{array}{l}-1.67 \\
(1.01)\end{array}$ & $32.511(<0.0001)$ \\
\hline Visoperceptual/visuospatial & 0.01 & -0.05 & -1.10 & $16.78(<0.0001)$ \\
\hline
\end{tabular}




\begin{tabular}{l|l|l|l|l}
\hline & $(0.71)$ & $(0.67)$ & $(1.08)$ & \\
\hline Language z score (BNT) & 0.13 & 0.14 & -0.55 & 3.12 \\
& $(0.87)$ & $(0.83)$ & $(1.21)$ & $(0.048)$ \\
\hline \hline \multicolumn{5}{l|l}{} \\
\hline \hline Attention/Working memory ${ }^{\star}$ & 4 & 11 & 42 & \\
\hline Executive $^{\star}$ & 0 & 4 & 26 & \\
\hline Memory* $^{*}$ & 1 & 5 & 31 & \\
\hline Visoperceptual/visuospatial $^{\star}$ & 0 & 4 & 26 & \\
\hline Language $^{\star}$ & 1 & 3 & 4 & \\
\hline \hline
\end{tabular}

$\mathrm{MCl}$ patients' scores were significantly worse than non-MCl patients' and healthy controls' $(p<.05$, Bonferroni correction). * Number of subjects impaired in one or more tests in this domain. In the healthy control group, no subjects showed impairments in more than one test, i.e., none fulfilled criteria for $\mathrm{MCl}$. Trail Making Test (TMT) part A (TMT A) and part B (TMT B), Symbol Digits Modalities Tests (SDMT); short version of the Boston Naming Test (BNT), Rey's Auditory Verbal Learning Test (RAVLT); Benton's Judgement of Line Orientation (JLO) and Visual Form Discrimination (VFD).

Table 3. Global atrophy results for healthy controls and Parkinson's disease patients according to $\mathrm{MCl}$ status, controlling for the effect of age and education.

\begin{tabular}{|c|c|c|c|c|}
\hline & $\begin{array}{c}\mathrm{HC} \\
\mathrm{n}=32 \\
\text { mean (SD) }\end{array}$ & $\begin{array}{c}\text { PD non-MCl } \\
\quad n=43 \\
\text { mean (SD) }\end{array}$ & $\begin{array}{c}\mathrm{PD} \mathrm{MCl} \\
\mathrm{n}=47 \\
\text { mean (SD) }\end{array}$ & $F(p)$ \\
\hline Global thickness (mm) & $2.49(0.09)$ & $2.47(0.10)$ & $2.41(0.10$ & $6.412(0.002)$ \\
\hline Total GM $\left(\mathrm{cm}^{3}\right)$ & 610.36 (51.79) & $605.06(59.68)$ & $589.95(57.85)$ & $3.652(0.029)^{\star}$ \\
\hline Subcortical GM $\left(\mathrm{cm}^{3}\right)$ & $168.97(20.07)$ & 173.14(20.98) & $171.02(18.44)$ & $1.533(0.220)^{\star}$ \\
\hline Lateral ventricles $\left(\mathrm{cm}^{3}\right)$ & $9.60(4.05)$ & $10.65(5.57)$ & $13.64(7.85)$ & $3.058(0.051)^{*}$ \\
\hline
\end{tabular}

*ANCOVA analyses with age, education and eICV as confounding variables. Global cortical thickness showed significant differences between $\mathrm{HC}$ and PD MCI patients $(p<0.006$, Bonferroni correction). Total GM showed significant differences between $\mathrm{HC}$ and $\mathrm{PD}$ non- $\mathrm{MCl}$ patients $(p=0.031$, Bonferroni correction). Mean lateral ventricular volumes showed significant differences between $\mathrm{HC}$ and PD MCI patients ( $p=.046$, Bonferroni correction). 


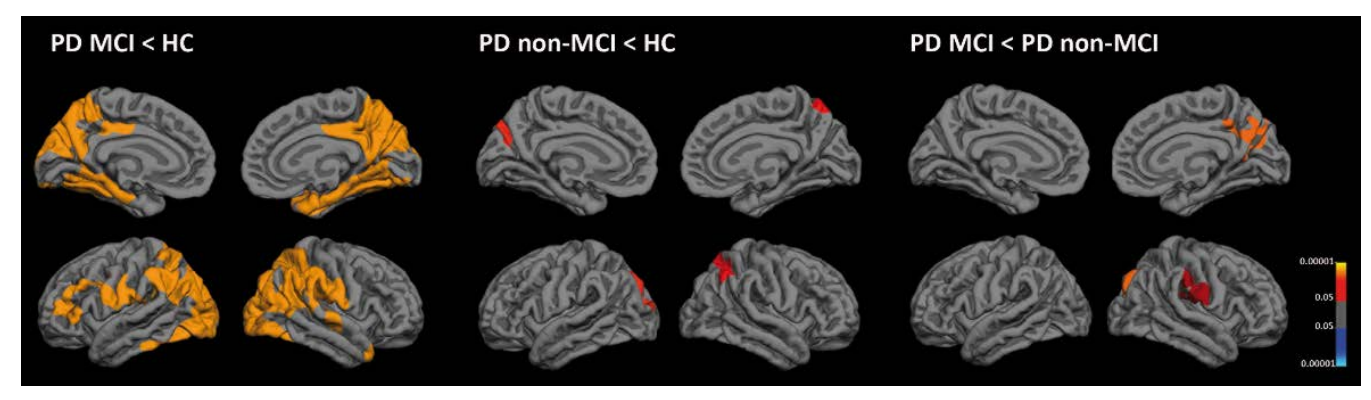

Figure 1. Vertex wise comparison of cortical thickness between healthy controls $(H C)$, Parkinson's disease patients without mild cognitive impairment (PD non-MCl) and Parkinson's disease patient with mild cognitive impairment (PD MCl), after controlling for the effect of age and education. The scale bar shows $p$ values. 


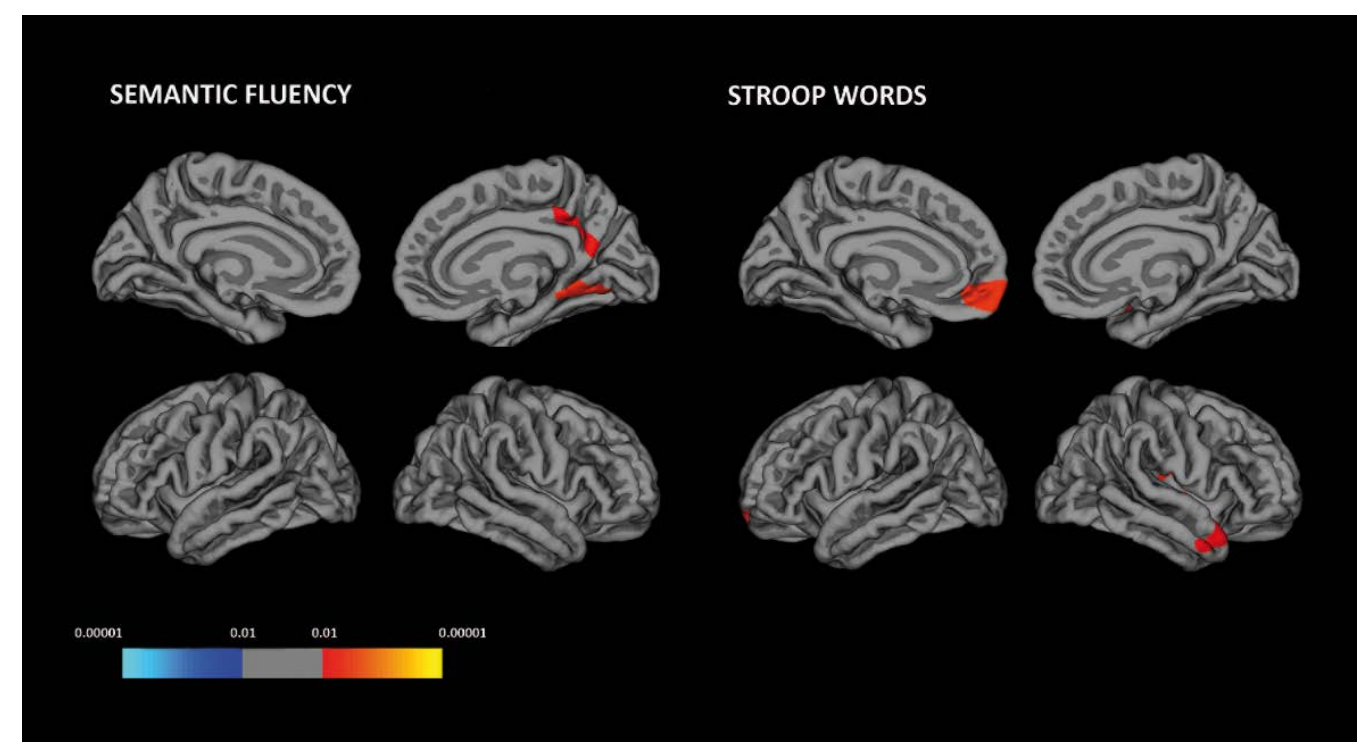

Figure 2. Significant correlation between cortical thickness and neuropsychological tests, after controlling age, education and gender effects. The scale bar shows $\mathrm{p}$ values. 
References

1. Foltynie T, Brayne CEG, Robbins TW, Barker RA. The cognitive ability of an incident cohort of Parkinson's patients in the UK. The CamPalGN study. Brain 2004;127:550560.

2. Muslimovic D, Post B, Speelman JD, Schmand B. Cognitive profile of patients with newly diagnosed Parkinson disease. Neurology 2005; 65:1239-1245.

3. Aarsland D, Brønnick K, Larsen JP, Tysnes OB, Alves G. Cognitive impairment in incident, untreated Parkinson disease: the Norwegian ParkWest study. Neurology 2009; 72:1121-1126.

4. Elgh E, Domellöf M, Linder J, Edström M, Stenlund H, Forsgren L. Cognitive function in early Parkinson's disease: a population-based study. Eur J Neurol 2009; 16:1278-1284.

5. Aarsland D, Andersen K, Larsen JP, Lolk A, Nielsen H, Kragh-Sørensen P. Risk of dementia in Parkinson's disease: a community-based, prospective study. Neurology 2001; 56:730-736.

6. Janvin CC, Larsen JP, Aarsland D, Hugdahl K. Subtypes of mild cognitive impairment in Parkinson's disease: progression to dementia. Mov Disord 2006; 21:1343-1349.

7. Pedersen KF, Larsen JP, Tysnes O-B, Alves G. Prognosis of mild cognitive impairment in early Parkinson disease: the Norwegian ParkWest study. JAMA Neurol 2013; 70:580-586.

8. Litvan I, Aarsland D, Adler CH, et al. MDS Task Force on mild cognitive impairment in Parkinson's disease: critical review of PD-MCI. Mov Disord 2011; 26:1814-1824.

9. Broeders M, Velseboer DC, de Bie R, et al. Cognitive change in newly-diagnosed patients with Parkinson's disease: a 5-year follow-up study. J Int Neuropsychol Soc . 2013; 19:695-708.

10. Caviness JN, Driver-Dunckley E, Connor DJ, et al. Defining mild cognitive impairment in Parkinson's disease. Mov Disord 2007; 22:1272-1277.

11. Litvan I, Goldman JG, Tröster Al, et al. Diagnostic criteria for mild cognitive impairment in Parkinson's disease: Movement Disorder Society Task Force guidelines. Mov Disord 2012; 27:349-356

12. Riekkinen P, Kejonen K, Laakso MP, Soininen H, Partanen K, Riekkinen M. Hippocampal atrophy is related to impaired memory, but not frontal functions in nondemented Parkinson's disease patients. Neuroreport 1998; 9:1507-1511.

13. Brück A, Kurki T, Kaasinen V, Vahlberg T, Rinne JO. Hippocampal and prefrontal atrophy in patients with early non-demented Parkinson's disease is related to cognitive impairment. J Neurol Neurosurg Psychiatry 2004; 75:1467-1469.

14. Tam CWC, Burton EJ, McKeith IG, Burn DJ, O'Brien JT. Temporal lobe atrophy on MRI in Parkinson disease with dementia: a comparison with Alzheimer disease and dementia with Lewy bodies. Neurology 2005; 64:861-865.

15. Camicioli R, Moore MM, Kinney A, Corbridge E, Glassberg K, Kaye JA. Parkinson's disease is associated with hippocampal atrophy. Mov Disord 2003;18:784-790.

16. Ibarretxe-Bilbao N, Ramírez-Ruiz B, Tolosa E, et al. Hippocampal head atrophy predominance in Parkinson's disease with hallucinations and with dementia. J Neurol 2008; 255:1324-1331.

17. Junqué $\mathrm{C}$, Ramírez-Ruiz B, Tolosa E, et al. Amygdalar and hippocampal MRI volumetric reductions in Parkinson's disease with dementia. Mov Disord 2005; 20:540-544.

18. Pereira JB, Junqué C, Bartrés-Faz D, Ramírez-Ruiz B, Marti M-J, Tolosa E. Regional vulnerability of hippocampal subfields and memory deficits in Parkinson's disease. Hippocampus 2013; 23:720-728.

19. Pereira JB, Junqué C, Martí MJ, Ramirez-Ruiz B, Bartrés-Faz D, Tolosa E. Structural brain correlates of verbal fluency in Parkinson's disease. Neuroreport 2009; 20:741744. 
20. Pereira JB, Junqué C, Martí M-J, Ramirez-Ruiz B, Bargalló N, Tolosa E. Neuroanatomical substrate of visuospatial and visuoperceptual impairment in Parkinson's disease. Mov Disord 2009; 24:1193-1199.

21. Ibarretxe-Bilbao N, Junque C, Tolosa E, et al. Neuroanatomical correlates of impaired decision-making and facial emotion recognition in early Parkinson's disease. Eur J Neurosci 2009; 30:1162-1171.

22. Baggio HC, Segura B, Ibarretxe-Bilbao N, et al. Structural correlates of facial emotion recognition deficits in Parkinson's disease patients. Neuropsychologia 2012; 50:21212128.

23. Filoteo JV, Reed JD, Litvan I, Harrington DL. Volumetric correlates of cognitive functioning in nondemented patients with Parkinson's disease. Mov Disord 2013 doi: $10.1002 / \mathrm{mds} .25633$

24. Beyer MK, Janvin CC, Larsen JP, Aarsland D. A magnetic resonance imaging study of patients with Parkinson's disease with mild cognitive impairment and dementia using voxel-based morphometry. J Neurol Neurosurg Psychiatry 2007; 78:254-259.

25. Song SK, Lee JE, Park H-J, Sohn YH, Lee JD, Lee PH. The pattern of cortical atrophy in patients with Parkinson's disease according to cognitive status. Mov Disord 2011; 26:289-296.

26. Yarnall AJ, Breen DP, Duncan GW et al. Characterizing mild cognitive impairment in incident Parkinson disease: The ICICLE-PD Study. Neurology 2014; 82:308-316.

27. Pereira JB, Ibarretxe-Bilbao N, Marti M-J et al. Assessment of cortical degeneration in patients with Parkinson's disease by voxel-based morphometry, cortical folding, and cortical thickness. Hum Brain Mapp $2012 ; 33: 2521-2534$.

28. Biundo $R$, Calabrese $M$, Weis $L$ et al. Anatomical correlates of cognitive functions in early Parkinson's disease patients. PLoS One 2013; 8(5):e64222.

29. Pagonabarraga J, Corcuera-Solano I, Vives-Gilabert $Y$ et al. Pattern of regional cortical thinning associated with cognitive deterioration in Parkinson's disease. PLoS One 2013; 8(1):e54980.

30. Hanganu A, Bedetti C, Jubault T et al. Mild cognitive impairment in patients with Parkinson's disease is associated with increased cortical degeneration. Mov Disord 2013; 28:1360-1369.

31 Pereira JB, Svenningsson P, Weintraub D, Brønnick K, Lebedev A, Westman E, Aarsland D. Initial cognitive decline is associated with cortical thinning in early Parkinson disease. Neurology. 2014 In press.

32. Daniel SE, Lees AJ. Parkinson's Disease Society Brain Bank, London: overview and research. J Neural Transm Suppl 1993; 39:165-172.

33. Dubois B, Burn D, Goetz C et al. Diagnostic procedures for Parkinson's disease dementia: recommendations from the movement disorder society task force. Mov Disord 2007; 22:2314-2324.

34. Sled JG, Zijdenbos AP, Evans AC. A nonparametric method for automatic correction of intensity nonuniformity in MRI data. IEEE Trans Med Imaging 1998; 17:87-97.

35. Fischl B, Liu A, Dale AM. Automated manifold surgery: constructing geometrically accurate and topologically correct models of the human cerebral cortex. IEEE Trans Med Imaging 2001; J20:70-80.

36. Ségonne F, Pacheco J, Fischl B. Geometrically accurate topology-correction of cortical surfaces using nonseparating loops. IEEE Trans Med Imaging 2007; 26:518-529.

37. Dale AM, Fischl B, Sereno MI. Cortical surface-based analysis. I. Segmentation and surface reconstruction. Neuroimage 1999; 9:179-194.

38. Dale AM, Sereno MI. Improved Localizadon of Cortical Activity by Combining EEG and MEG with MRI Cortical Surface Reconstruction: A Linear Approach. J Cogn Neurosci 1993; 5:162-176.

39. Fischl B, Dale AM. Measuring the thickness of the human cerebral cortex from magnetic resonance images. Proc Natl Acad Sci U S A 2000; 97:11050-11055.

40. Fischl B, Salat DH, Busa E et al. Whole brain segmentation: automated labeling of neuroanatomical structures in the human brain. Neuron 2002; 33:341-355.

41. Garcia-Garcia D, Clavero P, Gasca Salas C et al. Posterior parietooccipital hypometabolism may differentiate mild cognitive impairment from dementia in Parkinson's disease. Eur J Nucl Med Mol Imaging 2012; 39:1767-1777. 
42. Williams-Gray CH, Foltynie T, Brayne CEG, Robbins TW, Barker RA. Evolution of cognitive dysfunction in an incident Parkinson's disease cohort. Brain 2007; 130:17871798.

43. Williams-Gray CH, Evans JR, Goris A, et al. The distinct cognitive syndromes of Parkinson's disease: 5 year follow-up of the CamPalGN cohort. Brain 2009 ;132:29582969.

44. Ibarretxe-Bilbao N, Junque C, Segura B, Baggio HC, Marti MJ, Valldeoriola F, Bargallo $\mathrm{N}$, Tolosa E. Progression of cortical thinning in early Parkinson's disease. Mov Disord. (2012) 27: 1746-53

45. Dalaker TO, Zivadinov R, Ramasamy DP et al. Ventricular enlargement and mild cognitive impairment in early Parkinson's disease. Mov Disord 2011; 26:297-301.

46. Apostolova L, Alves G, Hwang KS et al. Hippocampal and ventricular changes in Parkinson's disease mild cognitive impairment. Neurobiol Aging 2012; 33:2113-2124.

47. Weintraub D, Doshi J, Koka D et al. Neurodegeneration across stages of cognitive decline in Parkinson disease. Arch Neurol 2011; 68:1562-1568.

48. Lezak MD. Neuropsychological assessment. Oxford: Oxford University Press; 2012. 
Aarsland D, Brønnick K, Larsen JP, Tysnes OB, Alves G, Norwegian ParkWest Study Group (2009): Cognitive impairment in incident, untreated Parkinson disease: the Norwegian ParkWest study. Neurology 72:1121-1126.

Apostolova L, Alves G, Hwang KS, Babakchanian S, Bronnick KS, Larsen JP, Thompson PM, Chou Y-Y, Tysnes OB, Vefring HK, Beyer MK (2012): Hippocampal and ventricular changes in Parkinson's disease mild cognitive impairment. Neurobiol Aging 33:2113-24.

Beyer MK, Janvin CC, Larsen JP, Aarsland D (2007): A magnetic resonance imaging study of patients with Parkinson's disease with mild cognitive impairment and dementia using voxel-based morphometry. J Neurol Neurosurg Psychiatry 78:254-259.

Biundo R, Calabrese M, Weis L, Facchini S, Ricchieri G, Gallo P, Antonini A (2013): Anatomical correlates of cognitive functions in early Parkinson's disease patients. PLoS One 8:e64222.

Broeders M, Velseboer DC, de Bie R, Speelman JD, Muslimovic D, Post B, de Haan R, Schmand B (2013): Cognitive change in newly-diagnosed patients with Parkinson's disease: a 5-year follow-up study. J Int Neuropsychol Soc 19:695-708.

Brück A, Kurki T, Kaasinen V, Vahlberg T, Rinne JO (2004): Hippocampal and prefrontal atrophy in patients with early non-demented Parkinson's disease is related to cognitive impairment. J Neurol Neurosurg Psychiatry 75:1467-9.

Camicioli R, Moore MM, Kinney A, Corbridge E, Glassberg K, Kaye JA (2003): Parkinson's disease is associated with hippocampal atrophy. Mov Disord 18:784-790.

Caviness JN, Driver-Dunckley E, Connor DJ, Sabbagh MN, Hentz JG, Noble B, Evidente VGH, Shill HA, Adler CH (2007): Defining mild cognitive impairment in Parkinson's disease. Mov Disord 22:1272-7.

Dalaker TO, Zivadinov R, Larsen JP, Beyer MK, Cox JL, Alves G, Bronnick K, Tysnes O-B, Antulov R, Dwyer MG, Aarsland D (2010): Gray matter correlations of cognition in incident Parkinson's disease. Mov Disord 25:629-33.

Dale AM, Fischl B, Sereno MI (1999): Cortical surface-based analysis. I. Segmentation and surface reconstruction. Neuroimage 9:179-94.

Dale AM, Sereno MI (1993): Improved Localizadon of Cortical Activity by Combining EEG and MEG with MRI Cortical Surface Reconstruction: A Linear Approach. J Cogn Neurosci 5:162-76.

Daniel SE, Lees AJ (1993): Parkinson's Disease Society Brain Bank, London: overview and research. J Neural Transm Suppl 39:165-72.

Elgh E, Domellöf M, Linder J, Edström M, Stenlund H, Forsgren L (2009): Cognitive function in early Parkinson's disease: a population-based study. Eur J Neurol 16:1278-84.

Filoteo JV, Reed JD, Litvan I, Harrington DL (2014): Volumetric correlates of cognitive functioning in nondemented patients with Parkinson's disease. Mov Disord 29:360-7.

Fischl B, Dale AM (2000): Measuring the thickness of the human cerebral cortex from magnetic resonance images. Proc Natl Acad Sci U S A 97:11050-11055.

Fischl B, Liu A, Dale AM (2001): Automated manifold surgery: constructing geometrically accurate and topologically correct models of the human cerebral cortex. IEEE Trans Med Imaging 20:70-80. 
Fischl B, Salat DH, Busa E, Albert M, Dieterich M, Haselgrove C, van der Kouwe A, Killiany R, Kennedy D, Klaveness S, Montillo A, Makris N, Rosen B, Dale AM (2002): Whole brain segmentation: automated labeling of neuroanatomical structures in the human brain. Neuron 33:341-355.

Foltynie T, Brayne CEG, Robbins TW, Barker RA (2004): The cognitive ability of an incident cohort of Parkinson's patients in the UK. The CamPaIGN study. Brain 127:550-60.

Garcia-Garcia D, Clavero P, Gasca Salas C, Lamet I, Arbizu J, Gonzalez-Redondo R, Obeso JA, Rodriguez-Oroz MC (2012): Posterior parietooccipital hypometabolism may differentiate mild cognitive impairment from dementia in Parkinson's disease. Eur $\mathrm{J} \mathrm{Nucl}$ Med Mol Imaging 39:1767-77.

Hanganu A, Bedetti C, Jubault T, Gagnon J-F, Mejia-Constain B, Degroot C, Lafontaine A-L, Chouinard S, Monchi O (2013): Mild cognitive impairment in patients with Parkinson's disease is associated with increased cortical degeneration. Mov Disord 28:1360-9.

Ibarretxe-Bilbao N, Junque C, Tolosa E, Marti M-J, Valldeoriola F, Bargallo N, Zarei M (2009): Neuroanatomical correlates of impaired decision-making and facial emotion recognition in early Parkinson's disease. Eur J Neurosci 30:1162-1171.

Ibarretxe-Bilbao N, Ramírez-Ruiz B, Tolosa E, Martí MJ, Valldeoriola F, Bargalló N, Junqué C (2008): Hippocampal head atrophy predominance in Parkinson's disease with hallucinations and with dementia. J Neurol 255:1324-31.

Janvin CC, Larsen JP, Aarsland D, Hugdahl K (2006): Subtypes of mild cognitive impairment in Parkinson's disease: progression to dementia. Mov Disord 21:1343-9.

Junqué C, Ramírez-Ruiz B, Tolosa E, Summerfield C, Martí M-J, Pastor P, Gómez-Ansón B, Mercader JM (2005): Amygdalar and hippocampal MRI volumetric reductions in Parkinson's disease with dementia. Mov Disord 20:540-4.

Lezak MD (2004): Neuropsychological Assessment. Oxford University Press.

Litvan I, Aarsland D, Adler CH, Goldman JG, Kulisevsky J, Mollenhauer B, Rodriguez-Oroz MC, Tröster Al, Weintraub D (2011a): MDS Task Force on mild cognitive impairment in Parkinson's disease: critical review of PD-MCI. Mov Disord 26:1814-24.

Litvan I, Aarsland D, Adler CH, Goldman JG, Kulisevsky J, Mollenhauer B, Rodriguez-Oroz MC, Tröster Al, Weintraub D (2011b): MDS Task Force on mild cognitive impairment in Parkinson's disease: critical review of PD-MCI. Mov Disord 26:1814-24.

Litvan I, Goldman JG, Tröster AI, Schmand B a, Weintraub D, Petersen RC, Mollenhauer B, Adler $\mathrm{CH}$, Marder K, Williams-Gray CH, Aarsland D, Kulisevsky J, Rodriguez-Oroz MC, Burn DJ, Barker R a, Emre M (2012): Diagnostic criteria for mild cognitive impairment in Parkinson's disease: Movement Disorder Society Task Force guidelines. Mov Disord 27:349-56.

Muslimovic D, Post B, Speelman JD, Schmand B (2005): Cognitive profile of patients with newly diagnosed Parkinson disease. Neurology 65:1239-45.

Pagonabarraga J, Corcuera-Solano I, Vives-Gilabert Y, Llebaria G, García-Sánchez C, Pascual-Sedano B, Delfino M, Kulisevsky J, Gómez-Ansón B (2013): Pattern of regional cortical thinning associated with cognitive deterioration in Parkinson's disease. PLoS One 8:e54980. 
Pedersen KF, Larsen JP, Tysnes O-B, Alves G (2013): Prognosis of mild cognitive impairment in early Parkinson disease: the Norwegian ParkWest study. JAMA Neurol 70:580-6.

Pereira JB, Ibarretxe-Bilbao N, Marti M-J, Compta Y, Junqué C, Bargallo N, Tolosa E (2012): Assessment of cortical degeneration in patients with Parkinson's disease by voxel-based morphometry, cortical folding, and cortical thickness. Hum Brain Mapp 33:2521-34.

Pereira JB, Junqué C, Bartrés-Faz D, Ramírez-Ruiz B, Marti M-J, Tolosa E (2013): Regional vulnerability of hippocampal subfields and memory deficits in Parkinson's disease. Hippocampus 23:720-8.

Pereira JB, Junqué C, Martí MJ, Ramirez-Ruiz B, Bartrés-Faz D, Tolosa E (2009a): Structural brain correlates of verbal fluency in Parkinson's disease. Neuroreport 20:741-744.

Pereira JB, Junqué C, Martí M-J, Ramirez-Ruiz B, Bargalló N, Tolosa E (2009b): Neuroanatomical substrate of visuospatial and visuoperceptual impairment in Parkinson's disease. Mov Disord 24:1193-9.

Pereira JB, Svenningsson P, Weintraub D, Brønnick K, Lebedev A, Westman E, Aarsland D (2014): Initial cognitive decline is associated with cortical thinning in early Parkinson disease. Neurology 82:2017-25.

Riekkinen P, Kejonen K, Laakso MP, Soininen H, Partanen K, Riekkinen M (1998): Hippocampal atrophy is related to impaired memory, but not frontal functions in nondemented Parkinson's disease patients. Neuroreport 9:1507-11.

Ségonne F, Pacheco J, Fischl B (2007): Geometrically accurate topology-correction of cortical surfaces using nonseparating loops. IEEE Trans Med Imaging 26:518-29.

Sled JG, Zijdenbos AP, Evans AC (1998): A nonparametric method for automatic correction of intensity nonuniformity in MRI data. IEEE Trans Med Imaging 17:87-97.

Song SK, Lee JE, Park H-J, Sohn YH, Lee JD, Lee PH (2011): The pattern of cortical atrophy in patients with Parkinson's disease according to cognitive status. Mov Disord 26:289-96.

Tam CWC, Burton EJ, McKeith IG, Burn DJ, O'Brien JT (2005): Temporal lobe atrophy on MRI in Parkinson disease with dementia: a comparison with Alzheimer disease and dementia with Lewy bodies. Neurology 64:861-5.

Weintraub D, Doshi J, Koka D, Davatzikos C, Siderowf AD, Duda JE, Wolk DA, Moberg PJ, Xie SX, Clark CM (2011): Neurodegeneration across stages of cognitive decline in Parkinson disease. Arch Neurol 68:1562-1568.

Williams-Gray CH, Evans JR, Goris A, Foltynie T, Ban M, Robbins TW, Brayne C, Kolachana BS, Weinberger DR, Sawcer SJ, Barker RA (2009): The distinct cognitive syndromes of Parkinson's disease: 5 year follow-up of the CamPalGN cohort. Brain 132:2958-2969.

Williams-Gray CH, Foltynie T, Brayne CEG, Robbins TW, Barker R a (2007): Evolution of cognitive dysfunction in an incident Parkinson's disease cohort. Brain 130:1787-98.

Yarnall AJ, Breen DP, Duncan GW, Khoo TK, Coleman SY, Firbank MJ, Nombela C, WinderRhodes S, Evans JR, Rowe JB, Mollenhauer B, Kruse N, Hudson G, Chinnery PF, O'Brien JT, Robbins TW, Wesnes K, Brooks DJ, Barker RA, Burn DJ (2014): Characterizing mild cognitive impairment in incident Parkinson disease: the ICICLE-PD study. Neurology 82:308-16. 
Supplementary Material Table 1. Cortical thickness for healthy controls and Parkinson's disease patients according to MCI status, after controlling for the effect of age and education.

\begin{tabular}{l|l|l|l|l}
\multicolumn{1}{c|}{ Cortical region } & $\begin{array}{c}\text { Size } \\
(\mathrm{mm} 2)\end{array}$ & $\begin{array}{r}\text { MNI } \\
\text { coordinates (x y z)* }\end{array}$ & $\begin{array}{c}\text { z- } \\
\text { Max }\end{array}$ & $\begin{array}{c}\text { Corrected } \\
\text { cluster p- } \\
\text { value }\end{array}$ \\
\hline HC > PD nonMCI & 2219.34 & $27.1-60.545 .0$ & 4.001 & 0.0020 \\
\hline RH Superior Parietal & 2398.29 & $-19.8-72.238 .0$ & 2.972 & 0.0013 \\
\hline LH Superior Parietal & 27428.22 & $27.4-60.045 .8$ & 5.660 & 0.0010 \\
\hline HC > PD MCI & 24385.79 & $-24.9-94.814 .1$ & 5.740 & 0.0001 \\
\hline RH Superior Parietal & & & & \\
\hline LH Lateral Occipital & 1580.07 & $53.1-26.537 .9$ & 3.291 & 0.0260 \\
\hline PD nonMCI > PD MCI & 2764.79 & $8.0-66.829 .8$ & 2.764 & 0.0003 \\
\hline RH Supramarginal & & &
\end{tabular}

* MNI305 space. Results were obtained using Monte Carlo simulation with 10.000 iterations applied to cortical thickness maps to provide clusterwise correction for multiple comparisons (1.3). Significant clusters were reported at $\mathrm{p}<0.05$. $\mathrm{z}$-Max indicates the maximum $-\log 10$ (pvalue) in the cluster. 
Supplementary Material Table 2. Cortical areas showing significant correlation between cortical thickness and neuropsychological tests, within PD patients group.

\begin{tabular}{|c|c|c|c|c|}
\hline Cortical region & $\begin{array}{l}\text { Coordinates } \\
\left(\begin{array}{l}\text { x y z })^{*}\end{array}\right.\end{array}$ & $\begin{array}{l}\text { Size } \\
\left(\mathrm{mm}^{2}\right)\end{array}$ & z-Max & $\begin{array}{l}\text { Corrected } \\
\text { cluster } \\
\text { p-value }\end{array}$ \\
\hline \multicolumn{5}{|l|}{ Stroop Words } \\
\hline R Superior frontal & $\begin{array}{lll}-13.9 & 41.4 & 13.5\end{array}$ & 1016.84 & 5.728 & 0.0002 \\
\hline R Fusiform & $\begin{array}{llll}-30.5 & -63.9 & -5.9\end{array}$ & 1430.51 & 5.327 & 0.0001 \\
\hline R Insula & $\begin{array}{lll}34.4 & -15.3 & 17.9\end{array}$ & 5406.54 & 4.868 & 0.0001 \\
\hline R Banksts & $\begin{array}{lll}-55.3 & -48.9 & 4.2\end{array}$ & 1556.88 & 4.708 & 0.0001 \\
\hline R Posterior cingulate & $\begin{array}{lll}-5.7 & -26.9 & 36.9 \\
\end{array}$ & 2820.44 & 3.966 & 0.0001 \\
\hline L Insula & $\begin{array}{lll}35.9 & -10.4 & 18.6\end{array}$ & 7124.40 & 6.664 & 0.0001 \\
\hline L Fusiform & $\begin{array}{lll}32.0 & -75.0 & -4.1\end{array}$ & 1783.32 & 5.145 & 0.0001 \\
\hline L Supramarginal & $\begin{array}{lll}57.2 & -23.8 & 37.7\end{array}$ & 2178.13 & 5.142 & 0.0001 \\
\hline L Precuneus & $\begin{array}{lll}5.7 & -63.8 & 32.0\end{array}$ & 1200.89 & 4.216 & 0.0001 \\
\hline L Superiorparietal & $\begin{array}{lll}33.6 & -35.3 & 36.2\end{array}$ & 688.49 & 3.258 & 0.0078 \\
\hline \multicolumn{5}{|l|}{ Stroop Colours } \\
\hline L Insula & $\begin{array}{lll}-31.2 & -23.8 & 15.3\end{array}$ & 1810.45 & 6.218 & 0.0001 \\
\hline L Posterior cingulate & $-5.5 \quad-31.0 \quad 34.9$ & 1741.69 & 5.662 & 0.0001 \\
\hline L Superior frontal & $\begin{array}{lll}-9.7 & 4.1 & 45.0\end{array}$ & 2140.27 & 5.101 & 0.0001 \\
\hline L Fusiform & $-30.5 \quad-65.8-4.3$ & 974.31 & 4.982 & 0.0005 \\
\hline L Inferior parietal & $\begin{array}{lll}-48.3 & -61.2 & 12.5\end{array}$ & 964.95 & 4.812 & 0.0006 \\
\hline L Precentral & $\begin{array}{lll}13.8 & -10.8 & 60.1\end{array}$ & 819.32 & 3.933 & 0.0017 \\
\hline R Insula & $\begin{array}{lll}32.6 & -20.3 & 16.5\end{array}$ & 5343.71 & 7.405 & 0.0001 \\
\hline $\mathrm{R}$ fusiform & $\begin{array}{llll}32.1 & -72.9 & -5.6\end{array}$ & 1797.47 & 6.397 & 0.0001 \\
\hline R Precuneus & $\begin{array}{lll}5.7 & -63.0 & 30.0\end{array}$ & 1820.89 & 4.630 & 0.0001 \\
\hline $\mathrm{R}$ middle temporal & $\begin{array}{lll}53.4 & -56.3 & 8.0\end{array}$ & 868.00 & 4.431 & 0.0008 \\
\hline R superior temporal & $\begin{array}{llll}42.5 & 4.9 & -21.6\end{array}$ & 806.48 & 4.252 & 0.0025 \\
\hline R superior frontal & $\begin{array}{lll}20.6 & 12.5 & 51.3\end{array}$ & 691.36 & 4.126 & 0.0075 \\
\hline
\end{tabular}




\begin{tabular}{|c|c|c|c|c|}
\hline R supramarginal & $\begin{array}{lll}34.0 & -35.0 & 36.2\end{array}$ & 1343.18 & 3.864 & 0.0001 \\
\hline R Paracentral & $6.3-22.9 \quad 51.0$ & 603.83 & 3.774 & 0.0165 \\
\hline $\mathrm{R}$ lingual & $22.2-50.2 \quad-3.5$ & 689.39 & 3.417 & 0.0077 \\
\hline R superior parietal & $26.3 \quad-67.9 \quad 26.2$ & 491.82 & 3.107 & 0.0406 \\
\hline \multicolumn{5}{|c|}{ Stroop Words and Colours } \\
\hline L fusiform & $-34.3-44.1 \quad-8.9$ & 2038.27 & 7.546 & 0.0001 \\
\hline L insula & $\begin{array}{lll}34.6 & -13.7 & 17.8\end{array}$ & 6865.11 & 7.153 & 0.0001 \\
\hline L precuneus & $\begin{array}{lll}-12.2 & -54.2 & 12.3\end{array}$ & 3555.51 & 5.765 & 0.0001 \\
\hline L superiorfrontal & $\begin{array}{lll}-9.8 & 4.7 & 43.4\end{array}$ & 2574.41 & 5.309 & 0.0001 \\
\hline L precentral & $\begin{array}{lll}50.8 & -0.5 & 37.7\end{array}$ & 705.52 & 4.235 & 0.0049 \\
\hline L supramarginal & $\begin{array}{lll}46.3 & -37.1 & 40.7\end{array}$ & 678.20 & 3.663 & 0.0074 \\
\hline L lateralorbitofrontal & $\begin{array}{lll}-41.2 & 25.8 & -10.9\end{array}$ & 453.99 & 3.565 & 0.0473 \\
\hline R superiortemporal & $\begin{array}{lll}44.2 & 1.1 & -19.2\end{array}$ & 9480.53 & 7.191 & 0.0001 \\
\hline R fusiform & $28.1 \quad-44.5-11.4$ & 3165.48 & 6.054 & 0.0001 \\
\hline R precuneus & $4.7 \quad-55.0 \quad 18.6$ & 3700.90 & 5.696 & 0.0001 \\
\hline R paracentral & $6.1-21.9 \quad 50.2$ & 682.05 & 5.126 & 0.0082 \\
\hline R rostralmiddlefrontal & $\begin{array}{lll}24.9 & 40.1 & 17.0\end{array}$ & 467.44 & -4.410 & 0.0499 \\
\hline R precentral & $\begin{array}{lll}54.3 & 1.2 & 36.3\end{array}$ & 870.57 & 4.095 & 0.0008 \\
\hline R superiorfrontal & $\begin{array}{lll}22.7 & 1.8 & 43.4\end{array}$ & 643.42 & 3.817 & 0.0116 \\
\hline \multicolumn{5}{|l|}{ TMT A } \\
\hline L superiortemporal & $\begin{array}{lll}45.9 & -37.3 & 12.4\end{array}$ & 2596.58 & -5.034 & 0.0001 \\
\hline L posteriorcingulate & $\begin{array}{lll}-5.2 & -30.0 & 34.7\end{array}$ & 2812.62 & -4.652 & 0.0001 \\
\hline L inferiorparietal & $\begin{array}{lll}-47.6 & -61.2 & 12.3\end{array}$ & 501.20 & -4.567 & 0.0330 \\
\hline L fusiform & $\begin{array}{lll}34.3 & -44.1 & -8.9\end{array}$ & 1030.37 & -4.067 & 0.0002 \\
\hline R superiortemporal & $\begin{array}{lll}39.8 & 5.2 & -23.1\end{array}$ & 5966.78 & -6.499 & 0.0001 \\
\hline $\mathrm{R}$ lingual & $\begin{array}{lll}7.2 & -66.7 & 5.0\end{array}$ & 2678.34 & -5.452 & 0.0001 \\
\hline
\end{tabular}




\begin{tabular}{|c|c|c|c|c|}
\hline R middletemporal & $\begin{array}{lll}54.1 & -54.4 & 10.3\end{array}$ & 894.92 & -4.879 & 0.0006 \\
\hline R precuneus & $8.0-51.5 \quad 20.9$ & 1454.84 & -3.957 & 0.0001 \\
\hline R precentral & $\begin{array}{lll}39.0 & -11.0 & 55.1\end{array}$ & 1442.20 & -3.345 & 0.0001 \\
\hline \multicolumn{5}{|l|}{ TMT B } \\
\hline R precuneus & $\begin{array}{lll}-5.3 & -55.8 & 20.0\end{array}$ & 635.93 & -3.845 & 0.0099 \\
\hline R fusiform & $\begin{array}{lll}-30.4 & -66.1 & -6.1\end{array}$ & 591.22 & -3.541 & 0.0145 \\
\hline \multicolumn{5}{|l|}{ SDMT } \\
\hline L precuneus & $\begin{array}{lll}-5.3 & -58.2 & 17.3\end{array}$ & 2789.11 & 6.323 & 0.0001 \\
\hline L fusiform & $\begin{array}{lll}35.4 & -42.4 & -8.7\end{array}$ & 1382.66 & 5.407 & 0.0001 \\
\hline L superiortemporal & $\begin{array}{lll}45.1 & -37.6 & 12.8\end{array}$ & 944.63 & 5.318 & 0.0006 \\
\hline L inferiorparietal & $\begin{array}{lll}-48.2 & -61.5 & 11.7\end{array}$ & 1515.09 & 3.858 & 0.0001 \\
\hline L superiortemporal & $\begin{array}{lll}47.7 & -17.5 & -0.5\end{array}$ & 580.28 & 3.378 & 0.0164 \\
\hline L superiorfrontal & $\begin{array}{lll}13.4 & 19.3 & 30.2\end{array}$ & 938.31 & 3.207 & 0.0006 \\
\hline R rostralmiddlefrontal & $\begin{array}{lll}23.8 & 41.2 & 17.8\end{array}$ & 3095.34 & -5.933 & 0.0001 \\
\hline R precuneus & $\begin{array}{lll}8.1 & -50.1 & 20.3\end{array}$ & 2054.89 & 5.896 & 0.0001 \\
\hline R supramarginal & $\begin{array}{lll}50.0 & -34.7 & 17.7\end{array}$ & 2941.42 & 5.577 & 0.0001 \\
\hline R fusiform & $29.1 \quad-52.5 \quad-8.5$ & 1631.70 & 5.347 & 0.0001 \\
\hline R superiortemporal & $\begin{array}{lll}42.6 & 7.0 & -22.2\end{array}$ & 1025.13 & 4.787 & 0.0002 \\
\hline \multicolumn{5}{|l|}{ Digits Backwards } \\
\hline R superiortemporal & $\begin{array}{lll}51.5 & 7.4 & -16.4\end{array}$ & 679.70 & 3.256 & 0.0117 \\
\hline \multicolumn{5}{|l|}{ Semantic Fluency } \\
\hline L posteriorcingulate & $\begin{array}{lll}-5.6 & -27.9 & 37.5\end{array}$ & 2460.93 & 5.147 & 0.0001 \\
\hline L fusiform & $\begin{array}{l}-34.3-43.0- \\
10.0\end{array}$ & 1153.99 & 5.021 & 0.0001 \\
\hline L insula & $\begin{array}{lll}-31.7 & -28.4 & 13.2\end{array}$ & 3103.69 & 4.589 & 0.0001 \\
\hline L bankssts & $\begin{array}{lll}53.0 & -39.4 & 7.2\end{array}$ & 1246.19 & 4.373 & 0.0001 \\
\hline $\mathrm{R}$ lingual & $22.3 \quad-46.4 \quad-4.6$ & 2858.65 & 6.853 & 0.0001 \\
\hline
\end{tabular}




\begin{tabular}{|c|c|c|c|c|}
\hline R precuneus & $\begin{array}{lll}4.6 & -55.2 & 19.8\end{array}$ & 2581.56 & 6.552 & 0.0001 \\
\hline R superiortemporal & $\begin{array}{lll}59.6 & -6.2 & 0.1\end{array}$ & 6365.59 & 5.248 & 0.0001 \\
\hline R middletemporal & $\begin{array}{llll}57.2 & -56.8 & 6.3\end{array}$ & 486.53 & 4.573 & 0.0427 \\
\hline R rostralmiddlefrontal & $\begin{array}{lll}25.4 & 39.8 & 16.7\end{array}$ & 862.24 & -4.000 & 0.0011 \\
\hline $\mathrm{R}$ inferiorparietal & $\begin{array}{lll}52.2 & -49.5 & 31.1\end{array}$ & 484.87 & 3.942 & 0.0436 \\
\hline \multicolumn{5}{|l|}{ Phonemic Fluency } \\
\hline L superiorfrontal & $\begin{array}{lll}13.1 & 42.5 & 14.2\end{array}$ & 817.27 & 5.176 & 0.0019 \\
\hline L superiortemporal & $\begin{array}{lll}-51.4 & -2.9 & -6.6\end{array}$ & 911.90 & 4.527 & 0.0007 \\
\hline L fusiform & $\begin{array}{lll}30.6 & -65.2 & -5.0\end{array}$ & 729.44 & 4.023 & 0.0041 \\
\hline L posteriorcingulate & $\begin{array}{lll}-13.6 & -11.2 & 38.7\end{array}$ & 529.75 & 3.413 & 0.0265 \\
\hline R superiortemporal & $\begin{array}{lll}44.0 & 1.1 & -19.4\end{array}$ & 2135.47 & 6.585 & 0.0001 \\
\hline R precuneus & $\begin{array}{lll}23.0 & -55.9 & 19.9\end{array}$ & 1612.36 & 5.257 & 0.0001 \\
\hline R postcentral & $\begin{array}{lll}37.7 & -6.1 & 16.7\end{array}$ & 1074.58 & 5.004 & 0.0003 \\
\hline R superiortemporal & $\begin{array}{lll}60.2 & -18.3 & -0.0\end{array}$ & 1108.06 & 4.228 & 0.0003 \\
\hline $\mathrm{R}$ lingual & $25.3 \quad-59.4 \quad-1.6$ & 972.18 & 3.573 & 0.0004 \\
\hline \multicolumn{5}{|l|}{ RAVLT TOTAL } \\
\hline L fusiform & $\begin{array}{lll}-29.9 & -64.5 & -2.1\end{array}$ & 823.29 & 5.415 & 0.0015 \\
\hline L inferiorparietal & $\begin{array}{lll}48.0 & -61.4 & 10.4\end{array}$ & 566.60 & 4.858 & 0.0188 \\
\hline L precuneus & $\begin{array}{lll}-5.9 & -56.8 & 23.9\end{array}$ & 1469.20 & 3.738 & 0.0001 \\
\hline L transversetemporal & $\begin{array}{lll}-48.5 & -20.5 & 7.2\end{array}$ & 488.49 & 3.581 & 0.03630 \\
\hline L precuneus & $\begin{array}{lll}8.9 & -41.5 & 45.7\end{array}$ & 522.68 & 3.434 & 0.02830 \\
\hline L caudalanteriorcingulate & $\begin{array}{lll}11.3 & 31.8 & 16.4\end{array}$ & 718.86 & 3.376 & 0.00470 \\
\hline L fusiform & $-29.9-64.5 \quad-2.1$ & 823.29 & 5.415 & 0.00150 \\
\hline R middletemporal & $\begin{array}{lll}53.5 & -57.2 & 7.4\end{array}$ & 5191.17 & 5.423 & 0.00010 \\
\hline R fusiform & $31.4-39.6-13.5$ & 2238.94 & 5.073 & 0.00010 \\
\hline R precuneus & $5.5-53.5 \quad 18.9$ & 1680.13 & 5.014 & 0.00010 \\
\hline RAVLT & & & & \\
\hline
\end{tabular}




\begin{tabular}{|l|lll|l|l|l|}
\hline L insula & 32.3 & -26.5 & 13.8 & 651.27 & 4.228 & 0.01450 \\
\hline JLO & -4.4 & -58.6 & 19.5 & 1019.66 & 4.380 & 0.00020 \\
\hline L precuneu & -28.9 & -71.7 & -4.2 & 714.35 & 3.710 & 0.00480 \\
\hline L fusiform & 6.6 & -56.7 & 36.4 & 1486.99 & 5.447 & 0.00010 \\
\hline R precuneus & 28.4 & -69.9 & -3.4 & 944.91 & 5.112 & 0.00050 \\
\hline R fusiform & 41.2 & 1.9 & -20.7 & 743.64 & 5.054 & 0.00680 \\
\hline R superiortemporal & 18.9 & 58.6 & 8.5 & 764.63 & -3.801 & 0.00590 \\
\hline R rostralmiddlefrontal & \multicolumn{7}{|l|}{} & & & \\
\hline VFD & 51.1 & 8.9 & -16.1 & 523.83 & 5.831 & 0.03930 \\
\hline R superiortemporal & 7.4 & -67.1 & 4.4 & 571.40 & 4.951 & 0.02570 \\
\hline R lingual & & & & & & \\
\hline
\end{tabular}

JLO: Judgment Line Orientation; RAVLT: Rey Auditory Verbal Learning Test; TMT:

Trail Making Test; VFD: Visual Form Discrimination; L= Left hemisphere; R= Right hemisphere. Results were obtained using Monte Carlo simulation with 10,000 iterations applied to CTh maps to provide clusterwise correction for multiple comparisons 2.3. Significant clusters were reported at $\mathrm{p}<0.05$. * MNI305 space. zMax indicates the maximum -log10(pvalue) in the cluster. 
Supplementary Material Table 3. Cortical areas showing significant correlation between cortical thickness and neuropsychological tests after controlling for the effects of age, education and gender, within PD patients group,.

\begin{tabular}{|c|c|c|c|c|}
\hline Cortical region & $\begin{array}{l}\text { Coordinates } \\
\left(\begin{array}{l}\mathbf{x} \mathbf{y} z)^{*}\end{array}\right.\end{array}$ & $\begin{array}{l}\text { Size } \\
\left(\mathrm{mm}^{2}\right)\end{array}$ & $\begin{array}{l}\text { z- } \\
\text { Max }\end{array}$ & $\begin{array}{l}\text { Corrected } \\
\text { cluster } \\
\text { p-value }\end{array}$ \\
\hline \multicolumn{5}{|l|}{ Semantic Fluency } \\
\hline R Lingual & $20.3 \quad-45.9 \quad-5.4$ & 657.55 & 6.051 & 0.0098 \\
\hline R Precuneus & $\begin{array}{lll}13.3 & -42.5 & 37.2\end{array}$ & 494.59 & 2.753 & 0.0398 \\
\hline \multicolumn{5}{|l|}{ Stroop P } \\
\hline L medialorbitofrontal & $-6.4 \quad 55.6-12.1$ & 651.88 & 3.686 & 0.0088 \\
\hline L superiortemporal & $\begin{array}{lll}44.2 & 4.5 & -20.4\end{array}$ & 533.79 & 3.092 & 0.0266 \\
\hline L insula & $\begin{array}{lll}33.0 & 10.1 & 11.1\end{array}$ & 634.09 & 4.132 & 0.0121 \\
\hline
\end{tabular}

Results were obtained using Monte Carlo simulation with 10,000 iterations applied to CTh maps to provide clusterwise correction for multiple comparisons 2.3. Significant clusters were reported at $\mathrm{p}<0.05 .{ }^{*}$ MNI305 space. $\mathrm{z}$-Max indicates the maximum $-\log 10$ ( $\mathrm{p}$ value) in the cluster. 
Supplementary figure 1. Significant correlation between cortical thickness and neuropsychological tests. The scale bar shows $\mathrm{p}$ values.

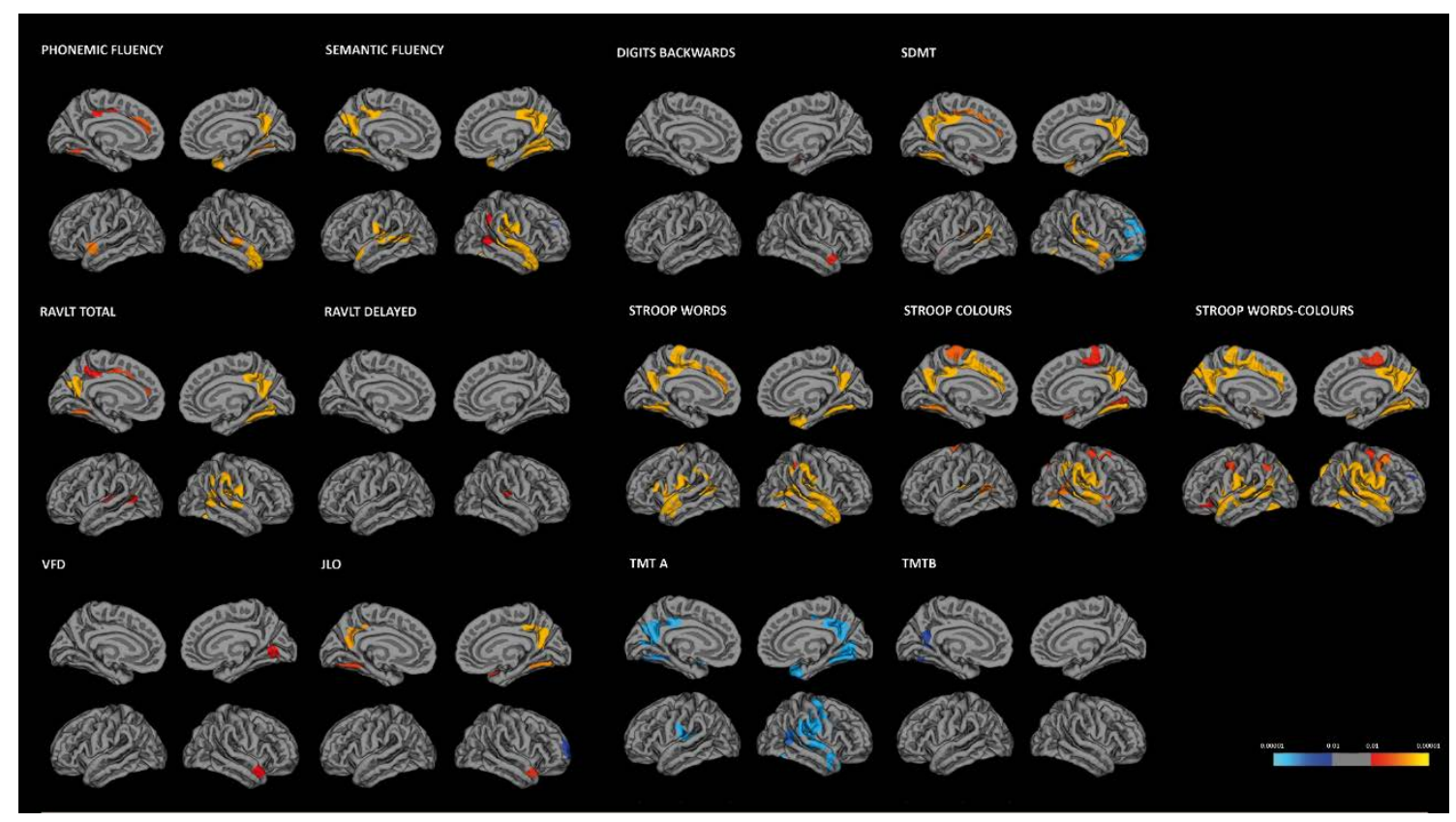


Supplementary figure 2. Mean cortical thickness of significant clusters from verexwise comparison between healthy controls (HC), Parkinson's disease patients without mild cognitive impairment (PD non-MCI) and Parkinson's disease patient with mild cognitive impairment (PD MCI), after controlling for the effect of age and education.
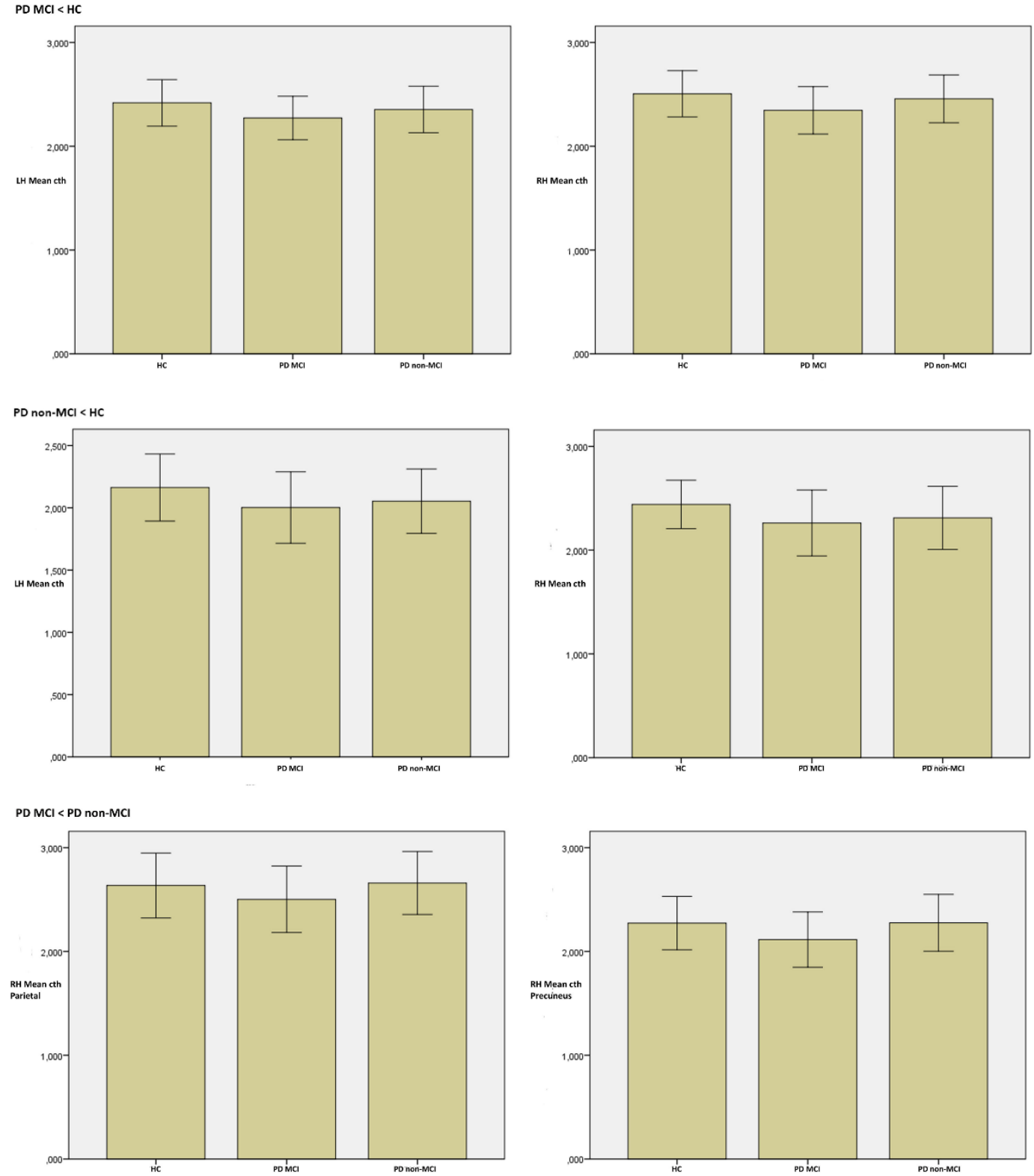